\title{
MODE AND MECHANISMS OF DEATH FOLLOWING ORTHOTOPIC HEART TRANSPLANTATION
}

\author{
Marmar Vaseghi, MD*, Nicolas Lellouche, MD`, Harry Ritter, BS, Gregg C. Fonarow, MD^, \\ Jignesh K. Patel, MD PhD ${ }^{\wedge}$, Jaime Moriguchi, MD ${ }^{\wedge}$, Michael C. Fishbein, MD\#, Jon A. \\ Kobashigawa, MD $^{\wedge \wedge}$, and Kalyanam Shivkumar, MD PhD \\ UCLA Cardiac Arrhythmia Center, David Geffen School of Medicine at UCLA, Los Angeles, CA \\ ^Ahmanson UCLA Cardiomyopathy Center, David Geffen School of Medicine at UCLA, Los \\ Angeles, CA \\ ${ }^{\wedge}$ UCLA Heart Transplantation Program, David Geffen School of Medicine at UCLA, Los Angeles, \\ $\mathrm{CA}$ \\ \#Department of Pathology \& Laboratory Medicine, David Geffen School of Medicine at UCLA, Los \\ Angeles, CA
}

\section{Abstract}

Background-Ventricular fibrillation (VF) is the primary mechanism of cardiac arrest in the vast majority of sudden death patients. Whether similar modes and mechanisms of death can be generalized to denervated hearts in orthotopic heart transplantation (OHT) patients is unknown.

Objective-The purpose of this study was to determine the mode and mechanisms of death in patients who have undergone cardiac transplantation.

Methods-We analyzed the outcomes of 628 patients who underwent OHT between January 1994 and December 2004. The mode of death was classified as either sudden death (SD) or nonsudden death (NSD). The first documented rhythm taken at the time of arrest was also reviewed to determine the mechanism of cardiac arrest.

Results-During a mean follow up of 76 months, 194 patients expired. Of these, the mode of death could be determined in 116 patients $(60 \%)$. Forty-one patients (35\%) died from SD and 75 patients $(65 \%)$ died of NSD. The first documented rhythm of death was available in 91 patients (26 SD and 65 NSD). The terminal rhythms in patients who died suddenly were: asystole (34\%), pulseless electrical activity (PEA) (20\%), and VF (10\%). In NSD patients, the terminal rhythms were asystole (73\%), followed by VF (7\%), and PEA (7\%), p<0.001 compared to SD patients.

Conclusion-SD represented the mode of death in 35\% of OHT patients. The main mechanisms underlying SD in this population were asystole and PEA, suggesting that denervation of the donor heart, among other post-transplant changes, may alter susceptibility to VF.

(C) 2009 The Heart Rhythm Society. Published by Elsevier Inc. All rights reserved.

Address for Correspondence: Kalyanam Shivkumar MD PhD UCLA Cardiac Arrhythmia Center Division of Cardiology, Department of Medicine 47-123 CHS, David Geffen School of Medicine at UCLA 10833 Le Conte Avenue Los Angeles CA 90095-1679 Phone: 3102066433 Fax: 3107946492 kshivkumar@mednet.ucla.edu.

these authors contributed equally to this study

Publisher's Disclaimer: This is a PDF file of an unedited manuscript that has been accepted for publication. As a service to our customers we are providing this early version of the manuscript. The manuscript will undergo copyediting, typesetting, and review of the resulting proof before it is published in its final citable form. Please note that during the production process errors may be discovered which could affect the content, and all legal disclaimers that apply to the journal pertain.

Conflicts of interest: None 


\section{Keywords}

heart transplantation; sudden death; ventricular fibrillation

\section{INTRODUCTION}

In the general population, sudden cardiac death claims an estimated 300,000 to 350,000 lives each year in the United States. $(1,2)$ Ischemic heart disease is the most common cause of SD, representing approximately $65 \%$ of cases.(3) Among patients with SD, ventricular fibrillation (VF) is the most common mechanism of cardiac arrest, occurring in up to two thirds of patients.(3) The autonomic nervous system appears to play a key role in the genesis of VF due to acute ischemia in this setting. (4-9)

Whether similar arrhythmic mechanisms underlie SD in the orthotopic heart transplant population remains unclear. Patients who have undergone orthotopic heart transplantation (OHT) represent a unique opportunity to explore the role of cardiac innervation, as posttransplant myocardial tissue has been shown to remain partially or completely denervated. $(10,11)$ Therefore, the purpose of this study was to establish the mode and mechanism of cardiac arrest among patients who have undergone OHT.

\section{METHODS}

\section{Patient Population}

All available data, including both inpatient and outpatient records, on 628 consecutive patients who underwent OHT at the UCLA Medical Center between January 1994 and December 2004 were analyzed retrospectively. During the follow-up period, 194 patients expired. Mortality data were confirmed by contacting family members whenever possible. Retrospective review of patient data was approved by our Institutional Review Board.

\section{Clinical Data}

Complete medical records for all expired patients were obtained and reviewed. These records were utilized to obtain information regarding the reasons for heart transplantation and history of cardiovascular risk factors (e.g. diabetes, hypertension, hypercholesterolemia). In addition, the most recent post-transplantation medical regimen was reviewed (i.e. immunosuppresive agents, angiotensin-converting enzyme inhibitors, statins, angiotensin receptor blockers, beta-blockers, anticoagulative agents, antiplatelet agents, antiarrhythmics, antibiotics). The most recently recorded heart rate and ejection fraction (LVEF) for each patient, while clinically stable, were also noted. The latter was measured by transthoracic echocardiography using the Simpson Method.

\section{Assessment of the mode of death}

The mode of death was defined as sudden cardiac death if unexpected cardiac arrest occurred within twenty-four hours after onset of any new symptoms.(12,13) Other deaths were classified as non-sudden death (NSD). Patients who experienced death due to trauma, suicide, or known intoxication were excluded from the study.

\section{Assessment of the cause of death}

To adjudicate the cause of death in OHT patients, an extensive analysis of all available information was performed by 3 of the authors for each death (MV, NL, KS). Causes of death noted in this population included: acute myocardial ischemia, rejection, sepsis, stroke, multiple organ failure, heart failure, cancer, acute hepatitis, and major bleeding. Acute 
myocardial ischemia was noted as the principal cause of death when an acute coronary occlusion was confirmed by autopsy or cardiac catheterization; or when patients with documented allograft coronary vasculopathy experienced electrocardiographic changes or a symptom complex (chest discomfort, shortness of breath) and elevated cardiac serum enzymes consistent with myocardial ischemia. Allograft rejection as the cause of death was determined by autopsy or endomycardial biopsy criteria. Sepsis was considered to have been the cause of death if acute evolving infection was found at autopsy, or if prior to expiration, the patients met the following criteria: (i) temperature $>38^{\circ} \mathrm{C}$ or $<36^{\circ} \mathrm{C}$, (ii) white blood cell count $>12,000$ or $<4000$ cells $/ \mathrm{mm} 3$ and (iii) an identified source of infection.(14) Multiple organ failure was defined as the failure of two or more of the following organ systems: cardiovascular, respiratory, renal or hematologic.(15) Only the primary cause of death was noted for each patient. All in-patient OHT patients were on telemetry.

\section{Assessment of the mechanism of death}

The first rhythm documented at the time of arrest leading to death, if available, was assessed to determine the mechanism of death. The mechanism of death was classified as VF, asystole, or pulseless electrical activity (PEA). When an original electrocardiogram recording was not available, the death summary and death notes were reviewed to determine the documentation of the mechanism of cardiac arrest.

\section{Use of Implantable Cardioverter Defibrillators (ICDs) in OHT Patients}

To assess the burden of VT/VF in OHT patients, a retrospective analysis of all device interrogation logs for patients who had undergone ICD implantation was performed. The reasons for device implantation, LVEF prior to implantation, and number of appropriate and inappropriate therapies were noted for all the patients.

\section{Statistical analysis}

Continuous variables were expressed as mean \pm standard deviation (SD) and statistical differences were assessed using the unpaired Student's $t$ test or Mann-Whitney test if necessary. ANOVA was used to compare continuous variables in the three groups, each representative of one mechanism of death. Categorical variables, expressed as numbers or percentages, were compared with the chi-square test or Fischer's exact test. A univariate analysis of variables was performed. Cumulative event rates (mortality) were calculated according to the Kaplan-Meier method in the overall population. All tests were 2-tailed and a p value $<0.05$ was considered statistically significant.

\section{RESULTS}

Six hundred and twenty eight adult patients were transplanted between January 1994 and December 2004. Of these, 194 died during follow-up. The overall mode and mechanism of death for the patient population is shown in Figure 1. The mean follow-up was $76 \pm 55$ months. Figure 2a shows the Kaplan-Meier curve for survival in the overall transplanted population. The mortality rate of the population at 3,5 , and 10 years were $22 \%, 24 \%$, and $37 \%$, respectively. The baseline characteristics of the 116 post-OHT patients $(60 \%, 85$ males, 31 females) on whom data on mode and mechanism of death were available are shown in Table 1. The mean age was 56 years, and $82 \%$ of patients were hospitalized at the time of death. The LVEF at the time of death was $48.5 \% \pm 13.9 \%$. The primary reasons for heart transplantation were ischemic or idiopathic cardiomyopathy in 59\% and $29 \%$ of patients, respectively. Medical treatment prior to death consisted of statins (28\%), angiotensin converting enzyme inhibitors or receptor blockers (22\%), beta-blockers (9\%) and amiodarone (9\%), Table 1. Immunosuppressive regiments included corticosteroids, 
cyclosporine, mycophenolate mofetil, and tacrolimus in $66 \%, 58 \%, 25 \%$, and $14 \%$ of cases, respectively.

In the 116 patients, the primary causes of death were sepsis (28\%), acute ischemia (24\%), followed by rejection (14\%), stroke (10\%), and multiple organ failure (7\%), Table 1 . The data to determine the mechanism of death, defined as the first documented rhythm of death, were available in 91 of our 116 patients $(78 \%)$.

\section{Autopsy}

Autopsy data were available in a total of 39 patients, $51 \%$ of patients in the SD group and $21 \%$ in the NSD group. The pathological processes underlying death in patients with SD included transplant coronary vasculopathy in $10(48 \%)$, acute rejection in $4(19 \%)$, ruptured iliac artery aneurysm in 1, and no anatomic cause of death in 6 (29\%).

\section{Comparison between SD and non-SD patients (Table 2)}

The overall incidence of SD in the 626 OHT patients was $5 \%$ at 5 years and $11 \%$ at 10 years, Figure $2 \mathrm{~b}$. In the 116 patients in whom the mode of death was determined, there were no differences in patients experiencing SD $(n=41)$ and NSD $(n=75)$ with respect to age, gender, LVEF prior to death, hypercholesterolemia, or hypertension. However, SD patients had a longer survival time before death $(38 \pm 37$ months vs. $16 \pm 26$ months, $\mathrm{p}<0.001)$, and were less likely to have diabetes than those with NSD ( $15 \%$ vs. $32 \%, \mathrm{p}=0.02)$. Acute ischemia was the main cause of death in the majority of patients with SD (61\%), compared to $4 \%$ in patients with NSD ( $<0.001)$. Rejection as the cause of death was comparable in both groups. Overall, SD accounted for the mode of death in $35 \%$ of patients.

Figures $3 \mathrm{a}$ and $3 \mathrm{~b}$ show the distribution of the three main mechanisms of death (asystole, PEA, and VF) in SD and NSD patients. The first documented rhythm at the time of death in SD patients was asystole (34\%), followed by PEA (20\%), and VF (10\%). The mechanism of death was not known in $37 \%$ of SD patients. In contrast, asystole was the terminal rhythm in $73 \%$ of patients with NSD ( $\mathrm{n}=55)$, followed by VF $(7 \%)$, and PEA (7\%) $(\mathrm{P}<0.001$ compared to SD patients). The mechanism of death was not known in 13\% of NSD patients.

Patients who died suddenly experienced PEA more often (20\% vs. $7 \%, \mathrm{p}=0.04)$ and had a lower incidence of asystole ( $34 \%$ vs. $73 \%$, p <0.0001) in comparison to NSD patients. However, the prevalence of VF as the first documented rhythm at the time of death was similar in both groups and low (10\% in SD vs. $7 \%$ in NSD, $\mathrm{p}=0.55)$.

\section{Comparison between patients who experienced asystole, PEA and VF (Table 3)}

Patients with asystole as the first documented rhythm were significantly older than those with PEA or VF (59 vs. 47 and 52 years respectively, $\mathrm{p}=0.007$ ). No significant differences were observed between these three groups with respect to treatment, including cardiovascular drugs, antibiotics, or inotropes. Regarding the cause of death, patients with PEA died more commonly from acute myocardial ischemia, whereas patients with asystole or VF died primarily from rejection and sepsis, respectively. As shown in Figure 3c, analysis of the mechanism of death in patients with SD due to acute ischemia $(n=18)$ was performed. Interestingly, the first documented rhythm in 9 patients was asystole (50\%), followed by 8 patients with PEA (44\%) and only 1 patient with VF (6\%).

\section{Implantation of ICD's in OHT patients}

Of the 628 patients in this study, $11(1.8 \%)$ patients ( 8 males, 3 females, age 51 115 , LVEF $41 \pm 9.9 \%$ ) underwent ICD placement. The reasons for device implantation were severe transplant vasculopathy with depressed $\mathrm{EF}(\mathrm{n}=6)$, recurrent syncope of unclear etiology with 
depressed EF ( $n=2)$, history of out-of-hospital cardiac arrest $(n=1)$, history of recurrent $\operatorname{NSVT}(n=1)$, and history of syncope in the donor with witnessed intraoperative VF of the donor heart $(\mathrm{n}=1)$. During $2.2 \pm 2.9$ years of follow-up, only the patient with recurrent NSVT experienced one appropriate shock. Two patients experienced a combined total of 6 inappropriate shocks and 5 inappropriate anti-tachycardia pacing therapies for sinus tachycardia during activity. There were no deaths in patients with ICDs.

\section{DISCUSSION}

\section{Major Findings}

This is the largest study to date analyzing the mode and mechanism of death in the postOHT population, particularly those who died in an in-hospital setting. The results demonstrate that (i) SD was the mechanism of death in $35 \%$ of this population (ii) the terminal rhythms resulting in sudden death, even in the presence of acute ischemia were, asystole or PEA, and least likely to be VF and (iii) asystole was also the most common terminal rhythm in the population presenting with NSD, where the primary cause of death was sepsis. These data provide new insights into the incidence and underlying mechanisms of sudden death after OHT.

\section{Incidence and Mode of Death}

Previous estimates of the incidence of SD in the transplant population have ranged from $10 \%$ to $50 \%$, likely due to both the small sample size and the inconsistent definition of SD. (16-19) Specifically, the time to sudden death from acute onset of symptoms has previously ranged from one to 12 hours. $(16,20)$ In this study, the incidence of SD was $35 \%$, and SD death was defined as death of cardiac origin occurring within 24 hours of the onset of symptoms.(12) This definition is in contrast to other studies of heart transplant patients, which were often non-specific and included non-cardiac causes of sudden death.(16,17) This particular definition also allowed for inclusion of all appropriate patients who experienced $\mathrm{SD}$, despite the retrospective nature of this study making the precise measurement of the time of onset of symptoms difficult.

The primary underlying causes of death in this cohort were sepsis, acute ischemia, and allograft rejection. SD in this population was primarily due to acute ischemia $(61 \%)$, with rejection accounting for $15 \%$ of deaths. In the subset of patients with NSD, the primary cause of death was sepsis (43\%) followed by rejection (13\%). Overall, two common profiles were observed in this patient population: those who died shortly after transplantation of NSD primarily due to sepsis, and those who survived past the first 16 months of transplantation, but succumbed to allograft vasculopathy, dying of SD primarily due to acute ischemia. Of note, the prevalence of rejection as the cause of death was similar in both profiles. This confirms a previous report that acute rejection can indeed cause SD, in addition to NSD, in heart transplant patients.(21)

\section{Mechanism of Sudden death in the Post-OHT Population}

The mechanism of sudden death in post-OHT patients is of particular interest, especially in comparison to those of the general population. Unlike the general population in whom ischemic heart disease is the most common cause of SD, frequently presenting with VF, $(3,22)$ asystole was the primary arrhythmic mechanism of cardiac arrest in the post-OHT population, representing $34 \%$ of SD (and 73\% of NSD) cases. PEA was the second most prevalent mechanism of SD, constituting $20 \%$ of cases. In fact, VF was an uncommon mechanism of death in post OHT patients. It should be noted that the majority of patient population (82\%) died in an inpatient setting. In both the SD and the NSD subgroups, it was the least frequent mechanism of cardiac arrest (10\% and 7\% of cases respectively), 
suggesting that transplanted hearts do not commonly fibrillate and VF does not commonly contribute to SD in this patient population.

It has previously been demonstrated that compared to the general population, patients hospitalized with advanced heart failure are more likely to experience asystole rather than VT/VF at expiration.(23) The average LVEF in this post-OHT population was $48.3 \%$, with no significant difference in EF between the SD and NSD subsets, suggesting that the mechanisms of SD were not unduly influenced by the effects of heart failure/ventricular dysfunction. However regional denervation of the heart in advanced heart failure may make this clinical scenario comparable to the transplant population.

In sharp contrast to the general population, ventricular fibrillation, even during acute ischemia, in the in-patient post-OHT population was rare. A potential explanation for this discrepancy is the significant role of the autonomic nervous system in the genesis and maintenance of malignant ventricular arrhythmias in innervated hearts, particularly during ischemia. Several studies have demonstrated abnormal neurohormonal remodeling in ischemic heart disease, both in humans and animal models of infarction.

Previous animal and human studies have demonstrated that sympathetic hyperinnervation, which follows the denervation of scarred myocardium, leads to an increased incidence of ventricular tachycardia (VT) and fibrillation. $(4-6,24,25)$ The areas of denervation and hyperinnervation do not respond normally to sympathetic stimulation demonstrating heterogeneous action potential duration prolongation and/or shortening and serving as sites of origin of inducible VT/VF.(7-9,26-28) OHT patients represent a unique clinical model of the denervated heart, and one potential explanation for our results is that denervation of the myocardium may prevent the development of VF. The lack cardiac of innervation has been further corroborated by heart rate variability data in our population, showing significantly depressed parameters.(29) However, cardiac reinnervation has been previously reported in small series of OHT patients 5-10 years following transplantation. $(10,11,30)$ Our study did not examine the extent of autonomic reinnervation in expired patients and its relationship to the incidence of VF. Establishing an experimental design to further study cardiac sympathetic innervation and subsequent risk and predictability of VF could help better elucidate the underlying mechanisms of cardiac arrest in this population. A role for cardiac innervation is supported by the finding that atrial fibrillation in stable cardiac transplant patients who are not in the immediate post-operative period is not observed (except during cardiac rejection and severe transplant vasculopathy).(29)

\section{Clinical Implications}

Understanding the mechanisms of sudden death in post-OHT patients is of increasing value for patient care. As surgical techniques and immunosuppressive regimens have been refined, survival rates have improved, accompanied by a shift in the primary cause of death. Shortterm mortality due to sepsis has been replaced by increasing morbidity and mortality due to allograft coronary vasculopathy. As the incidence of allograft vasculopathy rises, prevention of SD in this population will become increasing more important. Whether implantable cardioverter-defibrillators play a role in the prevention of SD in post-OHT patients remains controversial. A retrospective analysis of a small series of 10 post-OHT patients with ICDs suggested a therapeutic benefit in select patients.(31) However, in this study, of the 11 patients who underwent ICD implantation, only one patient with history of recurrent sustained VT (and no allograft vasculopathy) benefited from ICD therapy during follow up. The reduced incidence of VF in post-OHT patients, as demonstrated by these data, would further suggest a very limited role for these devices. 


\section{LIMITATIONS}

Due to the nature of this dataset, several unavoidable limitations should be considered. This study was retrospective in nature, and therefore, the mode of death was analyzable in only $60 \%$ of the expired post-OHT population. SD was defined to include any acute cardiac symptoms 24 hours prior to death. Therefore, it is possible that the proportion of all deaths falling into the "sudden" category was increased, and the proportion of all sudden natural deaths of cardiac origin reduced. Although a clearly better definition for sudden death is provided by Albert and colleagues(22), our definition was chosen to help interpret our data and was standardized compared to other papers in the heart transplant literature where definitions were not standardized. $(16,17)$

Determining the mechanism of SD is this population is further limited by the fact that most SD occurs in an out-patient setting. As a result, the mechanism of cardiac arrest was available in only $64 \%$ of the included SD cases. The rate of asystole as the mechanism of death may be overestimated due to a late diagnosis, and the prevalence of $\mathrm{VF}$ underestimated. However, $82 \%$ of the deaths in this study occurred in a monitored inpatient, setting excluding this important bias, but making the conclusions of this study more reflective of deaths in an in-patient setting, and not necessarily generalizable to the general OHT population. Also, the prevalence of VF in this OHT population was considerably lower than that expected in the general population. De Vreede-Swagemakers et al. found that, even when using a 24 hour definition for $\mathrm{SD}$, the rate of VF as the first documented rhythm was $55 \%$ in the general population, far higher than in this OHT-patients population (15\%).(13) It should be noted that if the vast majority of the $37 \%$ patients who died suddenly had died of VF the results would be similar to the general population in this regard. However, VF was still rare in patients who died suddenly due to acute myocardial ischemia with direct rhythm monitoring.

\section{CONCLUSIONS}

SD represents the mode of death in $35 \%$ of patients who have undergone OHT, particularly in an in-patient setting. The main mechanisms of death in this population are asystole and pulseless electrical activity, despite the fact that acute ischemia remains an important precipitant of death. Unlike the general population, VF is the least common mechanism of death, regardless of the mode of cardiac arrest (sudden or non-sudden). The lack of cardiac innervation in post-OHT patients could potentially explain the low incidence of VF observed in this population.

\section{Acknowledgments}

Kalyanam Shivkumar is supported by the NHLBI (R01HL084261).

\section{ABBREVIATIONS}

$\begin{array}{ll}\text { SD } & \text { sudden death } \\ \text { NSD } & \text { non-sudden death } \\ \text { OHT } & \text { orthotopic heart transplant } \\ \text { LVEF } & \text { left ventricular ejection fraction } \\ \text { PEA } & \text { pulseless electrical activity } \\ \text { VF } & \text { ventricular fibrillation }\end{array}$




\section{REFERENCES}

1. Myerburg, RJ.; Castellanos, A. Cardiac arrest and sudden cardiac death.. In: Braunwald, E., editor. Heart Disease: A Textbook of Cardiovascular Medicine. 4th Ed.. WB Saunders; Philadelphia, PA: 2001. p. 1473-82.

2. Huikuri HV, Castellanos A, Myerburg RJ. Sudden death due to cardiac arrhythmias. N Engl J Med. 2001; 345:1473-82. [PubMed: 11794197]

3. Podrid PJ. Myerburg RJ: Epidemiology and stratification of risk for sudden cardiac death. Clin Cardiol. 2005; 28:I3-11. [PubMed: 16450807]

4. Schwartz PJ, Vanoli E, Stramba-Badiale M, et al. Autonomic mechanisms and sudden death. New insights from analysis of baroreceptor reflexes in conscious dogs with and without a myocardial infarction. Circulation. 1988; 78:969-79. [PubMed: 3168199]

5. Schwartz PJ, La Rovere MT, Vanoli E. Autonomic nervous system and sudden cardiac death. Experimental basis and clinical observations for post-myocardial infarction risk stratification. Circulation. 1992; 85:I77-91. [PubMed: 1728509]

6. Chen PS, Chen LS, Cao JM, et al. Sympathetic nerve sprouting, electrical remodeling and the mechanisms of sudden cardiac death. Cardiovasc Res. 2001; 50:409-16. [PubMed: 11334845]

7. Kammerling JJ, Green FJ, Watanabe AM, et al. Denervation supersensitivity of refractoriness in noninfarcted areas apical to transmural myocardial infarction. Circulation. 1987; 76:383-93. [PubMed: 3038369]

8. Warner MR, Wisler PL, Hodges TD, et al. Mechanisms of denervation supersensitivity in regionally denervated canine hearts. Am J Physiol. 1993; 264:H815-20. [PubMed: 8384424]

9. Yoshioka K, Gao DW, Chin M, et al. Heterogeneous sympathetic innervation influences local myocardial repolarization in normally perfused rabbit hearts. Circulation. 2000; 101:1060-6. [PubMed: 10704175]

10. Quigg RJ, Rocco MB, Gauthier DF, et al. Mechanism of the attenuated peak heart rate response to exercise after orthotopic cardiac transplantation. J Am Coll Cardiol. 1989; 14:338-44. [PubMed: 2666478]

11. Stevenson LW, Sietsema K, Tillisch JH, et al. Exercise capacity for survivors of cardiac transplantation or sustained medical therapy for stable heart failure. Circulation. 1990; 81:78-85. [PubMed: 2297851]

12. Muller D, Agrawal R, Arntz HR. How sudden is sudden cardiac death? Circulation. 2006; 114:1146-50. [PubMed: 16952983]

13. de Vreede-Swagemakers JJ, Gorgels AP, et al. Out-of-hospital cardiac arrest in the 1990's: a population-based study in the Maastricht area on incidence, characteristics and survival. J Am Coll Cardiol. 1997; 30:1500-5. [PubMed: 9362408]

14. Nguyen HB, Smith D. Sepsis in the 21 st century: recent definitions and therapeutic advances. Am J Emerg Med. 2007; 25:564-71. [PubMed: 17543662]

15. Muckart DJ, Bhagwanjee S. American College of Chest Physicians/Society of Critical Care Medicine Consensus Conference definitions of the systemic inflammatory response syndrome and allied disorders in relation to critically injured patients. Crit Care Med. 1997; 25:1789-95. [PubMed: 9366759]

16. Chantranuwat C, Blakey JD, Kobashigawa JA, et al. Sudden, unexpected death in cardiac transplant recipients: an autopsy study. J Heart Lung Transplant. 2004; 23:683-9. [PubMed: 15366427]

17. Patel VS, Lim M, Massin EK, et al. Sudden cardiac death in cardiac transplant recipients. Circulation. 1996; 94:II273-7. [PubMed: 8901759]

18. Tatou E, Charvre P, Gomes MC, et al. [Long-term follow-up of anatomic heart transplantation. Apropos of 60 patients with a mean follow-up of 36 months]. Arch Mal Coeur Vaiss. 1998; 91:837-41. [PubMed: 9749174] 
19. Alexander RT, Steenbergen C. Cause of death and sudden cardiac death after heart transplantation. An autopsy study. Am J Clin Pathol. 2003; 119:740-8. [PubMed: 12760294]

20. Myerburg RJ, Kessler KM, Castellanos A. Sudden cardiac death. Structure, function, and timedependence of risk. Circulation. 1992; 85:I2-10. [PubMed: 1728501]

21. de Jonge N, Jambroes G, Lahpor JR, et al. Ventricular fibrillation during acute rejection after heart transplantation. J Heart Lung Transplant. 1992; 11:797-8. [PubMed: 1498146]

22. Albert CM, Ruskin JN. Risk stratifiers for sudden cardiac death (SD) in the community: primary prevention of SD. Cardiovasc Res. 2001; 50:186-96. [PubMed: 11334822]

23. Luu M, Stevenson WG, Stevenson LW, et al. Diverse mechanisms of unexpected cardiac arrest in advanced heart failure. Circulation. 1989; 80:1675-80. [PubMed: 2598430]

24. Cao JM, Chen LS, KenKnight BH, et al. Nerve sprouting and sudden cardiac death. Circ Res. 2000; 86:816-21. [PubMed: 10764417]

25. Cao JM, Fishbein MC, Han JB, et al. Relationship between regional cardiac hyperinnervation and ventricular arrhythmia. Circulation. 2000; 101:1960-9. [PubMed: 10779463]

26. Zipes DP, Barber MJ, Takahashi N, et al. Influence of the autonomic nervous system on the genesis of cardiac arrhythmias. Pacing Clin Electrophysiol. 1983; 6:1210-20. [PubMed: 6195641]

27. Dillon SM, Allessie MA, Ursell PC, et al. Influences of anisotropic tissue structure on reentrant circuits in the epicardial border zone of subacute canine infarcts. Circ Res. 1988; 63:182-206. [PubMed: 3383375]

28. Gough WB, Mehra R, Restivo M, et al. Reentrant ventricular arrhythmias in the late myocardial infarction period in the dog. 13. Correlation of activation and refractory maps. Circ Res. 1985; 57:432-42. [PubMed: 4028346]

29. Vaseghi M, Boyle N, Kedia R, et al. Supraventricular Tachycardia Following Orthotopic Heart Cardiac Transplantation. J Am Coll Cardiol. 2008 In Press.

30. Bengel FM, Ueberfuhr P, Schiepel N, et al. Effect of sympathetic reinnervation on cardiac performance after heart transplantation. N Engl J Med. 2001; 345:731-8. [PubMed: 11547742]

31. Ptaszek LM, Wang PJ, Hunt SA, et al. Use of the implantable cardioverter defibrillator in longterm survivors of orthotopic heart transplantation. Heart Rhythm. 2005; 2:931-3. [PubMed: 16171746] 


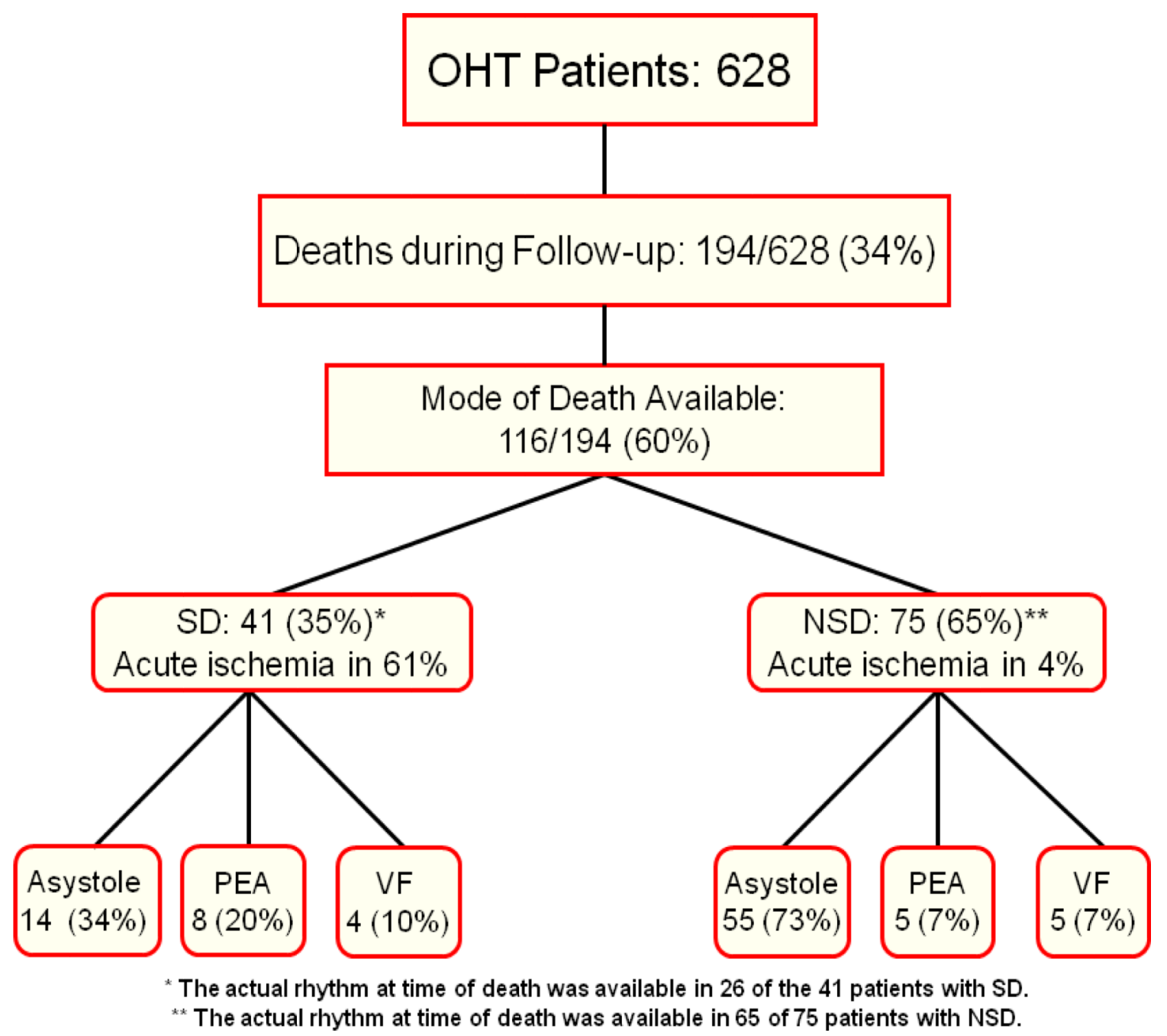

Figure 1.

Flow chart of study population. $\mathrm{OHT}=$ orthotopic heart transplantation, $\mathrm{SD}=$ sudden death, $\mathrm{NSD}=$ non-sudden death, $\mathrm{PEA}=$ pulseless electrical activity, $\mathrm{VF}=$ =entricular fibrillation 


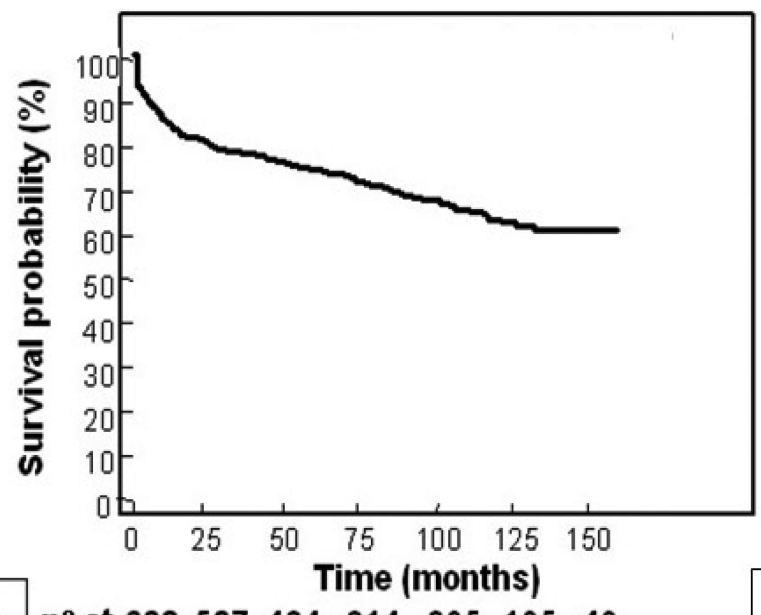

A $\quad n^{\circ}$ at $628527434314 \quad 205 \quad 105 \quad 49$ risk

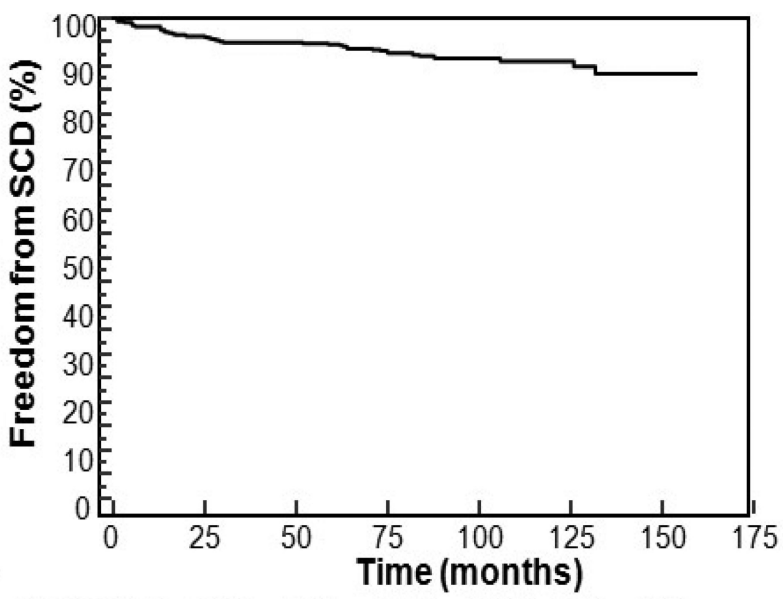

B $\quad n^{\circ}$ at $\begin{array}{lllllll}628 & 503 & 410 & 288 & 178 & 78 & 20\end{array}$ risk

Figure 2.

(A) Kaplan-Meier curve of survival in the overall transplant population; (B) Kaplan-Meier curve of the incidence of sudden death in the overall transplant population. 

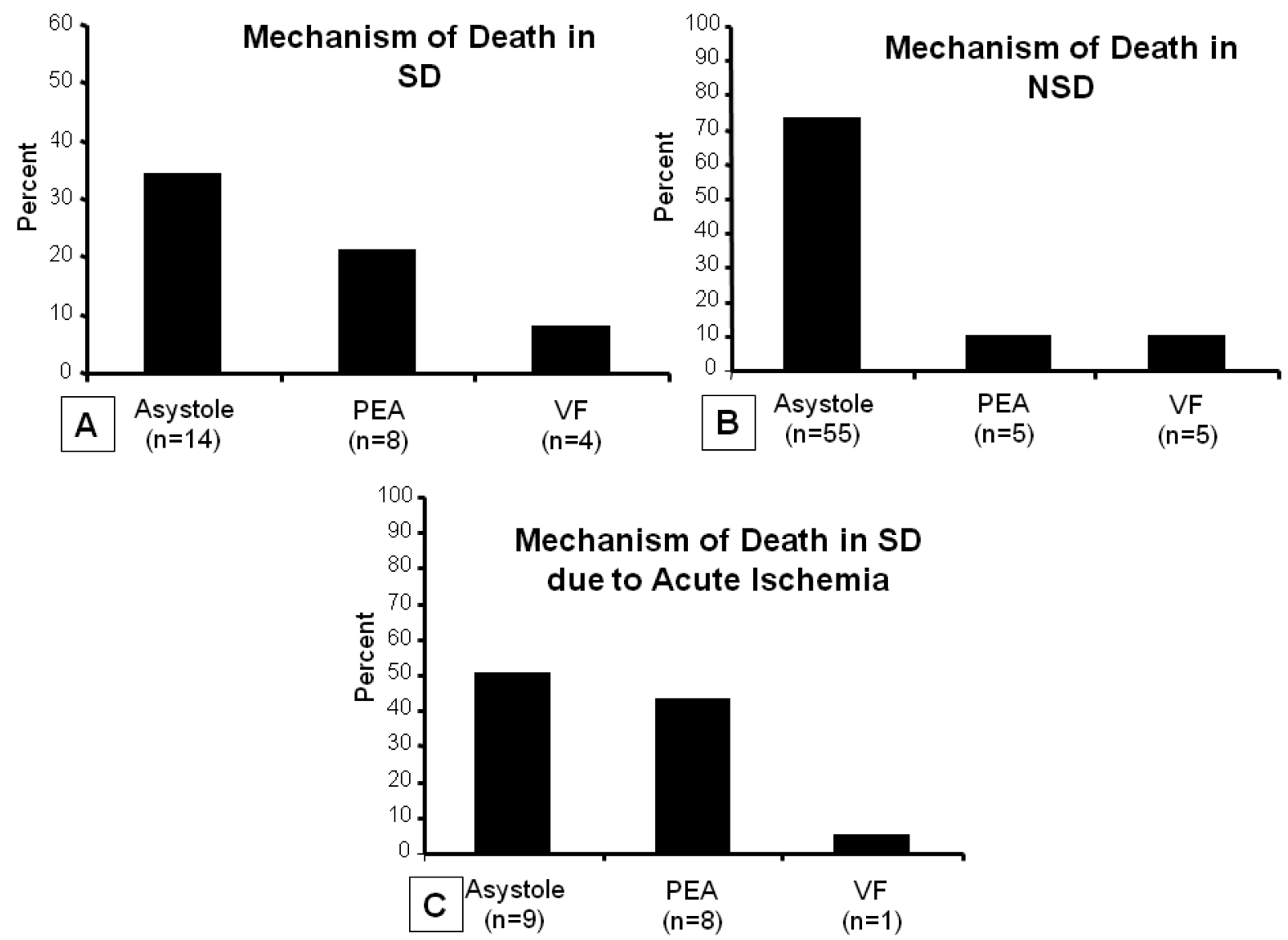

Figure 3.

(A) Mechanism of death in sudden death patients with documented rhythm at the time of death ( $\mathrm{n}=26)$; (B) Mechanism of death in non-sudden death patients with documented rhythm at the time of death $(n=65) ;(\mathbf{C})$ Mechanism of death in sudden death patients due to acute ischemia with documented rhythm at the time of death $(n=18)$. SD= sudden death, $\mathrm{NSD}=$ non-sudden death, $\mathrm{PEA}=$ pulseless electrical activity, $\mathrm{VF}=$ ventricular fibrillation. The mechanism of death was not known in $37 \%$ of SD (16 of 41) and 13\% (10 of 75) of NSD patients. 
Table 1

Baseline characteristics of patients who died $(n=116)$

\begin{tabular}{|c|c|}
\hline Age (years) & $56 \pm 14$ \\
\hline Male $(\%)$ & 73 \\
\hline \multicolumn{2}{|l|}{ Reason for transplant (\%) } \\
\hline Ischemic & 59 \\
\hline Idiopathic & 29 \\
\hline Valvular & 3 \\
\hline Post-Partum & 3 \\
\hline Congenital & 4 \\
\hline Others & 2 \\
\hline Hypertension (\%) & 39 \\
\hline Dyslipidemia (\%) & 42 \\
\hline Smokers (\%) & 17 \\
\hline Diabetes (\%) & 28 \\
\hline LVEF prior to death (\%) & $48.5 \pm 13.9$ \\
\hline In-patient prior to death $(\%)$ & 82 \\
\hline \multicolumn{2}{|c|}{ Treatments prior to Death $(\%)$} \\
\hline ACEI or ARB & 22 \\
\hline Beta-blockers & 9 \\
\hline Diuretics & 39 \\
\hline Anti-arrhythmics & 25 \\
\hline Statin & 28 \\
\hline Antiplatelets & 20 \\
\hline Inotrope & 45 \\
\hline Cyclosporine & 58 \\
\hline Azathioprine & 21 \\
\hline Corticosteroids & 66 \\
\hline Mycophenolate & 25 \\
\hline Tacrolimus & 14 \\
\hline Rapamycin & 3 \\
\hline Antibiotic therapy & 53 \\
\hline Antifungal therapy & 19 \\
\hline \multicolumn{2}{|c|}{ Principal Cause of Death $(\%)$ : } \\
\hline Acute ischemia & 24 \\
\hline Rejection & 14 \\
\hline Sepsis & 28 \\
\hline Multiple organ failure & 7 \\
\hline Stroke & 10 \\
\hline Heart Failure & 3 \\
\hline Cancer & 3 \\
\hline Major bleeding & 1 \\
\hline
\end{tabular}




\begin{tabular}{|ll|} 
Acute hepatitis & 1 \\
Unknown & 9 \\
\hline
\end{tabular}

$\mathrm{ACEI}=$ Angiotensin Converting Enzyme Inhibitors; ARB = Angiotensin Receptors Blockers; LVEF= Left Ventricular Ejection Fraction. 
Table 2

Characteristics of SD and NSD patients

\begin{tabular}{|c|c|c|c|}
\hline Age (years) & SD patients $(n=41) 52 \pm 15$ & NSD patients $(n=75) 58 \pm 13$ & p 0.02 \\
\hline Male $(\%)$ & 76 & 72 & 0.67 \\
\hline Time to death (months) & $38 \pm 37$ & $16 \pm 26$ & $<0.001$ \\
\hline LVEF before death (\%) & $48.1 \pm 13.8$ & $48.4 \pm 14.8$ & 0.91 \\
\hline In-patients prior to death (\%) & 51 & 99 & $<0.001$ \\
\hline Autopsy (\%) & 49 & 19 & $<0.001$ \\
\hline Baseline heart rate (bpm) & $101 \pm 25$ & $107 \pm 24$ & 0.25 \\
\hline \multicolumn{4}{|l|}{ Reason for transplant (\%) } \\
\hline Ischemic cardiomyopathy & 46 & 65 & 0.047 \\
\hline \multicolumn{4}{|l|}{ Cause of death $(\%)$} \\
\hline Acute ischemia & 61 & 4 & $<0.001$ \\
\hline Rejection & 15 & 13 & 0.85 \\
\hline Sepsis & 0 & 43 & $<0.001$ \\
\hline \multicolumn{4}{|l|}{ Mechanism of death (\%) } \\
\hline $\mathrm{VF}$ & 10 & 7 & 0.55 \\
\hline Asystole & 34 & 73 & $<0.001$ \\
\hline PEA & 20 & 7 & 0.04 \\
\hline Unknown & 36 & 13 & 0.004 \\
\hline \multicolumn{4}{|l|}{ Treatment before death (\%) } \\
\hline Beta-blockers & 15 & 5 & 0.09 \\
\hline ACEI or ARB & 37 & 13 & 0.004 \\
\hline Statin & 46 & 17 & $<0.001$ \\
\hline Diuretics & 49 & 33 & 0.10 \\
\hline Inotrope & 15 & 65 & $<0.001$ \\
\hline Antibiotics & 32 & 64 & $<0.001$ \\
\hline Anticoagulation & 7 & 23 & 0.04 \\
\hline Antiplatelets & 34 & 12 & 0.005 \\
\hline Hypertension (\%) & 49 & 33 & 0.10 \\
\hline Diabetes (\%) & 15 & 35 & 0.02 \\
\hline Hyperlipidemia (\%) & 49 & 39 & 0.29 \\
\hline
\end{tabular}

$\mathrm{ACEI}=$ Angiotensin Converting Enzyme Inhibitors; $\mathrm{ARB}=$ Angiotensin Receptor Blockers; bpm $=$ beats per minute LVEF $=$ Left Ventricular Ejection Fraction; NSD= Non-Sudden Death; PEA= Pulseless Electrical Activity; SD= Sudden death; VF= Ventricular Fibrillation. 
Table 3

Characteristics of patients who died primarily from VF, PEA or asystole

\begin{tabular}{|c|c|c|c|c|}
\hline & Asystole $(n=69)$ & PEA $(n=13)$ & VF (n=9) & $\mathbf{p}$ \\
\hline Age (years) & $59 \pm 12$ & $47 \pm 17$ & $52 \pm 13$ & 0.007 \\
\hline Male (\%) & 78 & 54 & 78 & 0.17 \\
\hline Time to death (months) & $23 \pm 33$ & $32 \pm 33$ & $28 \pm 31$ & 0.64 \\
\hline LVEF before death (\%) & $49 \pm 13$ & $42 \pm 20$ & $48 \pm 15$ & 0.35 \\
\hline In-patients before death (\%) & 94 & 85 & 89 & 0.45 \\
\hline Baseline heart rate (bpm) & $108 \pm 27$ & $100 \pm 17$ & $102 \pm 27$ & 0.63 \\
\hline \multicolumn{5}{|l|}{ Reason for transplant (\%) } \\
\hline Ischemic & 70 & 31 & 56 & 0.03 \\
\hline \multicolumn{5}{|l|}{ Cause of death (\%) } \\
\hline Ischemic & 16 & 62 & 22 & 0.002 \\
\hline Rejection & 9 & 23 & 44 & 0.01 \\
\hline Sepsis & 42 & 8 & 11 & 0.02 \\
\hline \multicolumn{5}{|l|}{ Mode of death (\%) } \\
\hline SD & 20 & 62 & 44 & 0.006 \\
\hline Treatment prior to death $(\%)$ & 9 & 15 & 0 & 0.46 \\
\hline Beta-blockers & 26 & 23 & 22 & 0.95 \\
\hline ACEI or ARB & 23 & 38 & 44 & 0.26 \\
\hline Statins & 41 & 46 & 66 & 0.33 \\
\hline Diuretics & 59 & 23 & 78 & 0.02 \\
\hline Inotrope & 65 & 46 & 66 & 0.41 \\
\hline Antibiotic Therapy Antiplatelets & 17 & 31 & 22 & 0.53 \\
\hline Hypertension (\%) & 36 & 54 & 22 & 0.30 \\
\hline Diabetes (\%) & 32 & 23 & 33 & 0.81 \\
\hline Hyperlipidemia (\%) & 43 & 38 & 44 & 0.94 \\
\hline
\end{tabular}

$\mathrm{ACEI}=$ Angiotensin Conversion Enzyme Inhibitors; $\mathrm{ARB}=$ Angiotensin Receptors Blockers; $b p m=$ beats per minute; LVEF $=$ Left Ventricular Ejection Fraction; PEA = Pulseless Electrical Activity; SD = Sudden death; VF = Ventricular Fibrillation. 